\title{
Strengthening Bridges with Prestressed CFRP Strips
}

\author{
Tomasz Siwowski, Piotr Żóltowski \\ Rzeszow University of Technology \\ Civil Engineering and Environmental Faculty \\ Promost Consulting Sp. z o.o., Rzeszow, Poland \\ e-mail: siwowski@prz.edu.pl, zoltowski@ promost.pl
}

\begin{abstract}
Limitation of bridge's carrying bearing capacity due to aging and deterioration is a common problem faced by road administration and drivers. Rehabilitation of bridges including strengthening may be applied in order to maintain or upgrade existing bridge parameters. The case studies of strengthening of two small bridges with high modulus prestressed CFRP strips have been presented in the paper. The first one - reinforced concrete slab bridge - and the other - composite steel-concrete girder bridge - have been successfully upgraded with quite new technology. In both cases the additional CFRP reinforcement let increasing of bridge carrying capacity from 15 till 40 metric tons. The CFRP strip prestressing system named Neoxe Prestressing System (NPS), developed by multi-disciplinary team and tested at full scale in Rzeszow University of Technology, has been also described in the paper.
\end{abstract}

Key words: bridge strengthening, CFRP strips, prestressing,

\section{Introduction}

Among many strengthening methods commonly used for upgrading existing bridges the plate bonding technique has been shown to be applicable to many rehabilitation issues in bridge engineering. The steel plate bonding had started to be used in the mid sixties and it was quite extensively applied during the seventies and eighties of the last century. However, two main limitations with using steel plates have been recognized, namely the risk of corrosion and that steel plates are quite heavy to lift and laborious to mount. Consequently if the plate bonding method was going to be used more widespread, a invention was needed to find a material that does not corrode, is strong and stiff and yet lightweight. Carbon fibre reinforced polymer (CFRP) laminates fulfilled these demands. In the late eighties the Swiss EMPA started to use CFRP strips for strengthening and in 1991 the first bridge in Switzerland was strengthened [1]. The use of CFRP laminates (strips, sheets) in strengthening and repair works have gone through a big development during last years. Composite materials are becoming increasingly popular in the bridge industry for strengthening purposes. These materials, particularly CFRP, 
offer several advantages such as resistance to corrosion, a high strength to weight ratio, and almost unlimited delivery length, thus eliminating the need for joints. Moreover by prestressing the laminate, the ultra high tensile strength of the composite material can be utilized and more advantages are brought to the strengthening technique.

During the past 20 years it had been developed several various prestressing systems for post tensioning CFRP strips. The first one was invented by Leonhardt, Andrä \& Partners in cooperation with University of Leipzig, Germany, and comprehensively tested in Swiss EMPA institute [2]. After about 10 years of using on site the German system was improved and its second generation is named Sika LEOBA CarboDur II. The second system available on the market is Sika StressHead invented in Swiss EMPA institute [3]. The main drawback of this system is the need to embed the steel anchorages deeply in concrete of strengthened structure. In early 2000's the Swiss company S\&P Clever Reinforcement Company AG introduced the new system for CFRP strips prestressing. The $S \& P$ system consisted of steel plates, which create anchorages for composite strips fixed between steel and concrete surface. In USA the main works on development of CFRP prestressing systems were carried out at University of Missouri-Rolla [4], [5]. All of the systems mentioned above have the steel anchorage blocks. However the mechanical anchorages are sometimes too complicated to handle. Hence a new technique is developed to control the interfacial stresses. Recently it has been introduced the new system without anchorages with gradually decreased prestressing along a strip towards the ends. In this method the stiffness of the adhesive is modified by applying the heat to the adhesive. By doing this the high shear stress value is reduced and distributed over a larger area.The special preheating device has been invented to accelerate a time of setting the adhesive and thus to adjust the force transferred into concrete surface [6].

Today in Poland upgrading RC bridges in bending with CFRP strips is the widely accepted strengthening method. A large number of bridges all over the country has been strengthened with this technique. Many researchers have performed tests and derived calculation theories in this field. Some of them have been recently involved in development of CFRP prestressing systems. The Polish modification of Sika LEOBA CarboDur II system has been recently introduced by IBDM institute (Warsaw), but not yet applied on site [7]. This paper briefly describes the features of the new prestressing and anchorage system for externally bonded CFRP strips, which was developed by multi-disciplinary team and tested at Rzeszow University of Technology [8,9]. The first field applications of the system, carried out successfully on two small bridges (concrete and steel), have been also described in the paper.

\section{The NPS system for prestressing of CFRP strips}

The Neoxe Prestressing System (NPS) consists of two main elements: the steel plate anchorages mounted on both ends of CFRP strip and the stretching device. The system contains two kinds of anchorages: active anchorage, which is combined with stretching device, and the passive one. The entire system with the CFRP strip equipped with the steel anchorages and mounted on experimental pilot beam is shown in Fig.1. The both anchorages are made up of two high quality steel plates, which create a pocket for strip's ends. The strips of determined length, resulting from the design procedure of retrofitted bridge, are delivered on site as ready-to-install, i.e. with two steel anchorages mounted on both strip ends. 


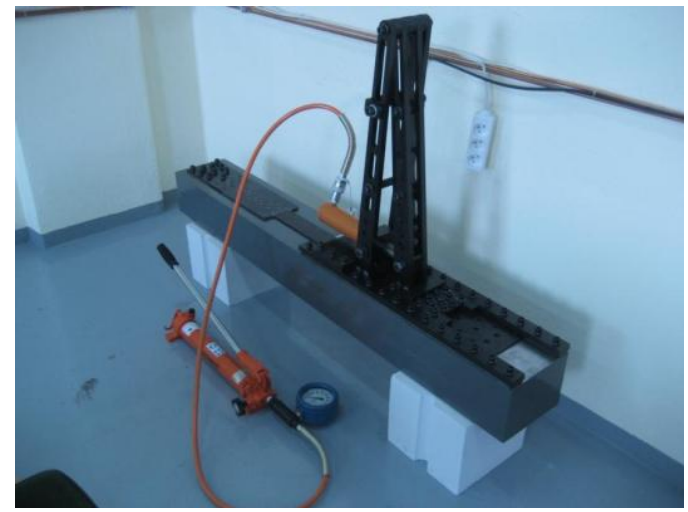

Figure1: Experimental assembly of NPS system; active anchorage along with the stretching device (right); passive anchorage fixed to the steel beam (left)

The active anchorage has two sets of holes: the first set is used to fix reaction block and transfer the force from stretching device. The second set is to fix the strip to the surface of element to be strengthened. Depending on the design parameters (i.e. quality of concrete, cover thickness, etc.) the size of steel plates and number/location of holes can be adjusted. The end's of strip are pre-fixed in the steel anchorage pocket, combining bonding of both materials with special epoxy resin-based multi-component glue heated to cure temperature, followed by gripping of both materials with small rivets. The strip anchorages transfer the prestressing force from stretching device to the element by bonding, rivet gripping and friction simultaneously (Fig.2).
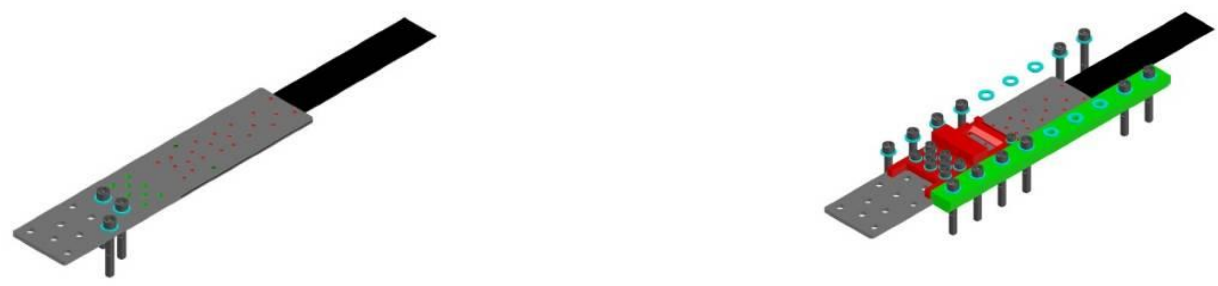

Figure 2: Steel anchorages; passive anchorage mounted on the CFRP strip (left); active anchorage with leading rails and reaction block (right)

Before strip to be prestressed the passive anchorage is fixed with nuts to steel bolts previously embedded in concrete or screwed to girder's steel flanges. During tentative fixing a strip (without glue underneath) the active anchorage is inserted into the space between two leading rails of the stretching device, which have earlier been fixed to an element. The leading rails enable to move the anchorage towards the force action and simultaneously hold it down to element base. The rails on one end are joined together with the bridge element constituting the stationary reaction block for the stressing device, whereas the second reaction block is screwed to the surface of active anchorage. The tongs-shaped stressing device is opened out by hydraulic jack under a pressure of maximum 700 bars. The ends of the tongs are inserted 
into the reaction blocks of the active anchorage and afterwards opened effectively stressing CFRP strip (Fig.3). When the tongs are opening out the strip is stressed up to the target force. The level of prestressing is exactly controlled with hydraulic gauge. The first preliminary stressing is made to verify a distance between the strip and an element's bottom surface and the quality of passive anchorage fixation. If the distance is too large, such location is marked and reprofilation of a element's surface is performed, while the strip is removed.
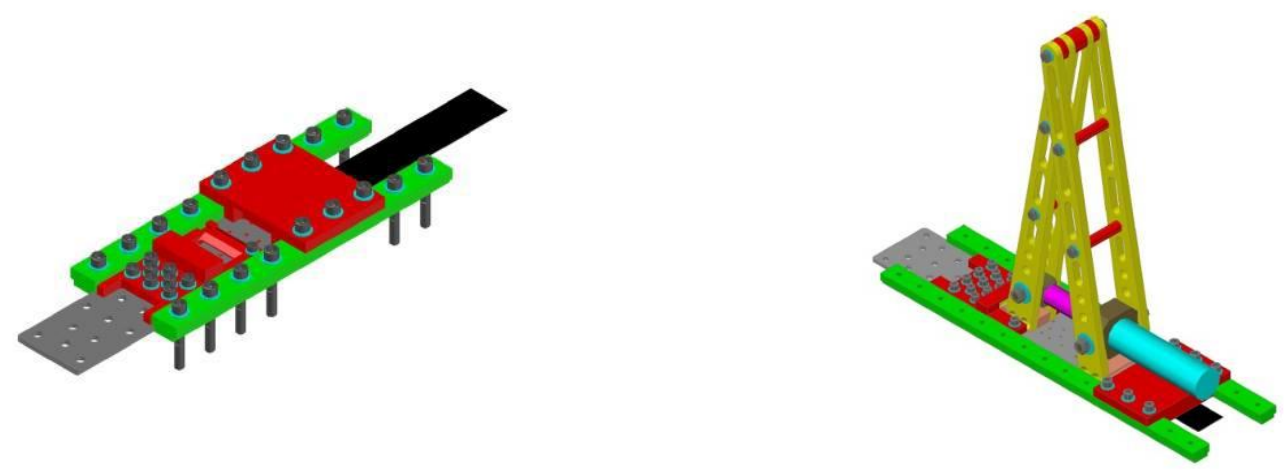

Figure 3: Active anchorage inserted into leading rails with both reaction blocks (left); complete stretching device with tongs and hydraulic jack (right)

After the reprofilation (if needed), both the element's surface and the strip are coated with a special epoxy based glue, followed by the reinstallation of strip to element. The following steps are performed: passive anchorage is screwed to the anchor bolts fixed to element, the active anchorage is placed into the space between the leading rails of the stressing device, the tongs are installed, the strip is tensioned to required force level. During slow stressing, the extruded epoxy glue excess is removed. When the active anchorage is positioned in its final location, an operator drills holes in concrete base or steel flange using the steel anchorage plate as template, and installs anchor bolts. Then the fixing nuts are screwed. After finishing of this operation the stressing device together with rails and reaction blocks are disassembled and the edges of the strip are cleaned again. The next strip may be installed (if needed).

\section{Strengthening of a concrete bridge with NPS}

The first on-site application of the NPS system was carried out on a small single span concrete slab bridge, built in 1948. The general view of the bridge is shown in Fig.4. The length of the span is $5,50 \mathrm{~m}$ and the total width $8,20 \mathrm{~m}$. The concrete slab with the thickness of $0,55 \mathrm{~m}$ is uniaxially reinforced with $22 \mathrm{~mm}$ rebars spaced every $0,18 \mathrm{~m}$ (i.e. $21,1 \mathrm{~cm}^{2} / \mathrm{m}$ ). Transverse reinforcement was very unreliable - the NDT test detected a few $10 \mathrm{~mm}$ bars with irregular spacing. The volume of $1,95 \mathrm{~cm}^{2} / \mathrm{m}$ was assumed in the bridge carrying capacity assessment. Concrete was in very good condition - no cracks, spalling, losses and defects were observed. The material tests carried out on $94 \mathrm{~mm}$ core samples taken from the slab revealed the high compressive strength of concrete, i.e. about 45,0 $\mathrm{MPa}$. Additionally the yield strength of the rebars was established in the laboratory as about $200 \mathrm{MPa}$. 


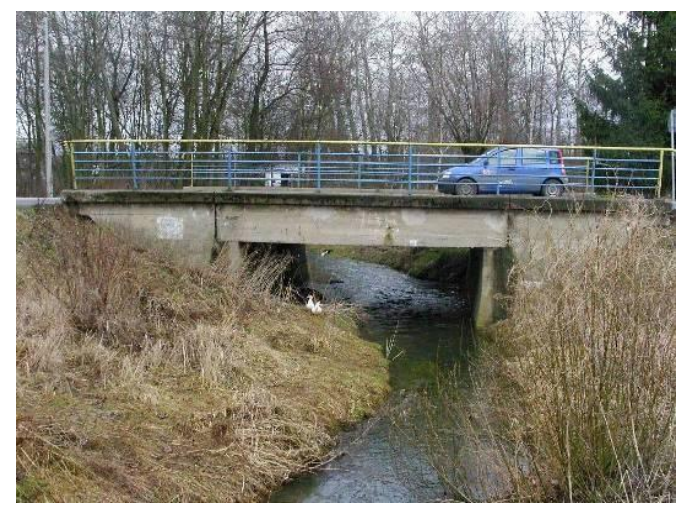

Figure 4: The concrete bridge before strengthening

The existing carrying capacity of the bridge was assessed. As it was far below the road administration requirements, it has been decided to strengthen the bridge. The most effective method of concrete slab strengthening was the use of CFRP strips. As the required level of strengthening in terms of service capacity in longitudinal direction was about $50 \%$ of existing carrying capacity, while the deficit was only on lower bending reinforcement, the prestressed CFRP strips were used for better efficiency of strengthening. The CFRP strips were also applied in transverse direction of the slab, but in this case their prestressing was not required. The simple comparative calculations have been carried out to establish the number of CFRP strips (in both directions) and the level of their prestressing. The final arrangement of additional CFRP reinforcement of the concrete span is shown in Figure 5. For longitudinal strengthening 12 CFRP strips of Neoxeplate 614HM type were used spaced with the transverse distance of $0,80 \mathrm{~m}$ (in the middle part of slab) and $0,56 \mathrm{~m}$ (in the both side parts). The strips with the length of $4720 \mathrm{~mm}$ were prepared and equipped with steel anchorages before delivery on construction site.

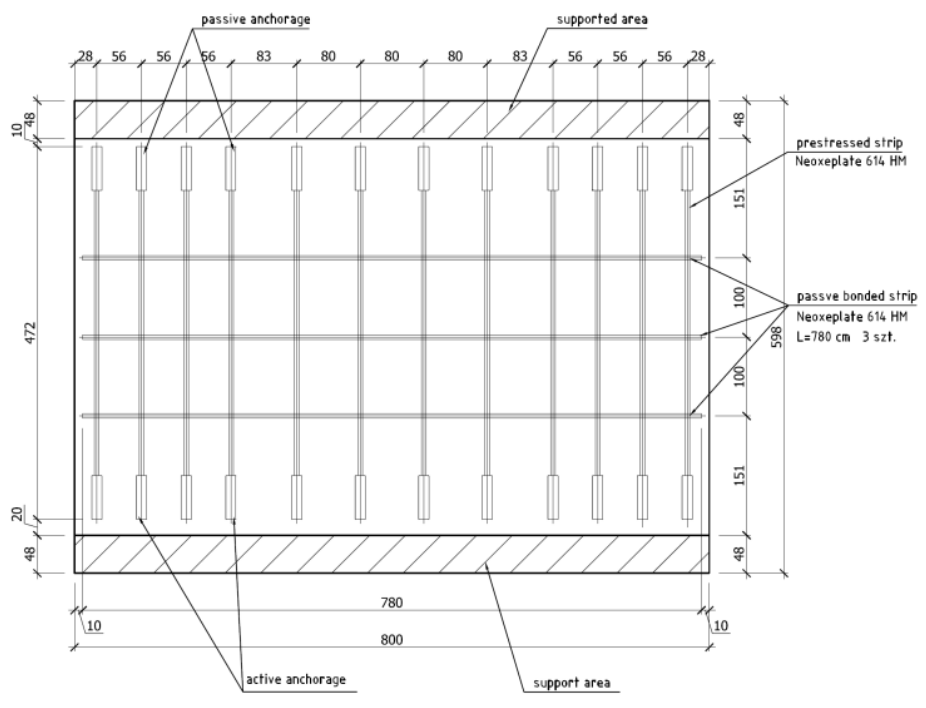

Figure 5: The final arrangement of CFRP reinforcement 
The shop assembled steel anchorages were designed especially for this application. The special Hilti HST M16×215 type anchors were used for bolting each anchorage to the bottom surface of concrete slab (Fig.6, left). For each steel anchorage six anchors were used. Before strip tensioning an adhesive was applied on strips and concrete surface's. The strips were tensioned with a hydraulic jack up to $75 \mathrm{kN}$ (Fig.6, right). Assembling the prestressed strips was followed by bonding three passive CFRP strips Neoxeplate 614HM type, which were used as a complementary transverse reinforcement. These strips were bonded in the middle part of slab with spacing of 1,00 m. After the CFRP strips installation the entire bottom surface was covered with concrete surface protection material. Moreover the steel anchorages were protected against corrosion with special paint. The whole strengthening process with active and passive CFRP strips was very effective and took only one day on site. No limitation of traffic was necessary during strengthening process. The case demonstrated that prestressing of the CFRP strips could be successfully undertaken under common site conditions.
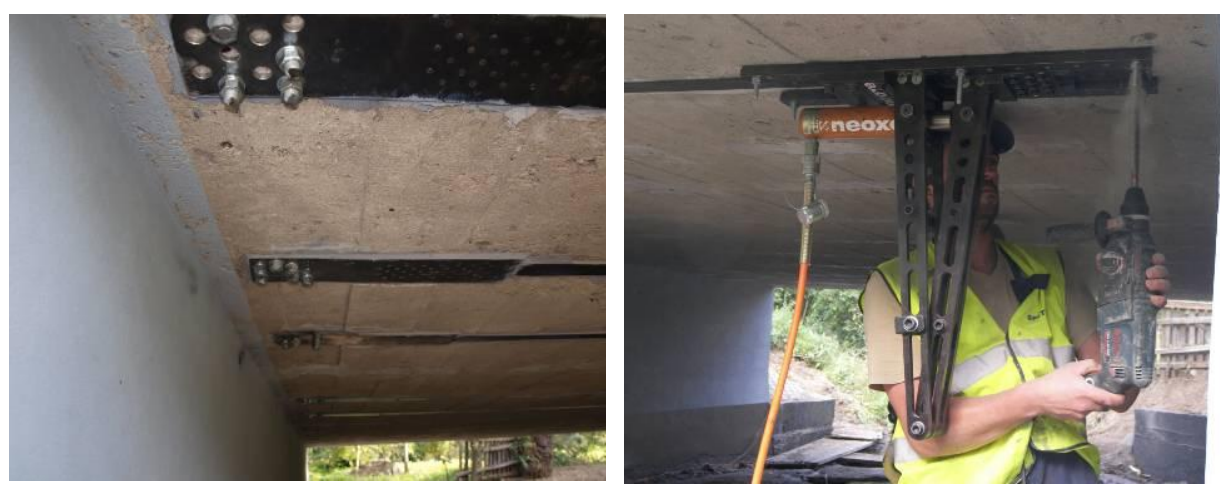

Figure 6: Steel anchorages bolted to bottom surface (left); stretching device on site (right)

\section{Strengthening of a composite steel-concrete bridge with NPS}

The second on-site application of NPS was carried out on single span composite steel-concrete bridge. General view of bridge is shown in Fig.7. The length of the span is 15,3 m and total width $8,2 \mathrm{~m}$ (after widening, performed simultaneously with upgrading). The span consisted of five INP 550 steel I-beam girders and 20 to $27 \mathrm{~cm}$ thick composite concrete slab. Steel girders were previously strengthened with steel plates, welded to the beam's bottom flanges. Material tests performed on $94 \mathrm{~mm}$ core samples taken from concrete slab have revealed good compressive strength of about 40,0 MPa. Concrete surface has shown some small defects, which must have occurred by the time of casting. The existing carrying capacity was assessed and it was found, that bridge service capacity was far below requirements of road administration. Calculations have revealed that concrete slab and webs of girders could bear higher service loads, while the stresses were exceeded in the bottom plate of steel girders. Additionally bridge had very unfavorable transverse cooperation of girders and slab, so it benefited from adding proper cross-girder system. Therefore post-tensioned CFRP strips of Neoxeplate 614 HM type were installed on the steel girders. Each girder was strengthened with only one CFRP strip. The system anchorages were bolted to bottom flanges with M16 10.9 class bolts. 


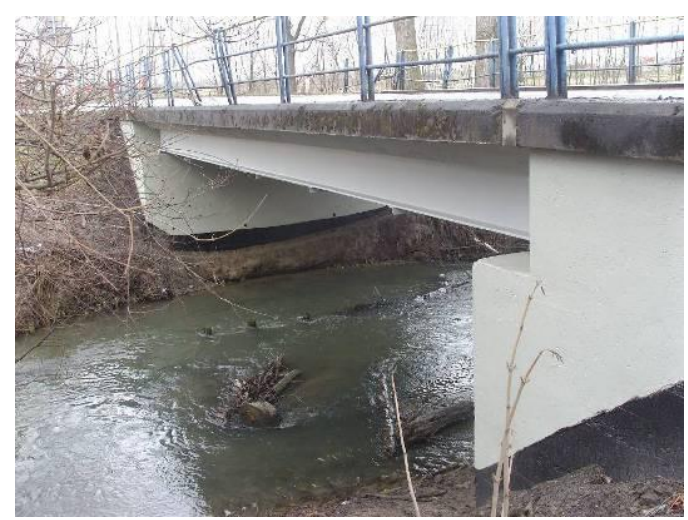

Figure 7: The steel - concrete before rehabilitation

Details of the reinforcement are shown in Fig.8. Prestressing procedure was similar to the one described above with concrete bridge, however a temporary working platform was suspended from cross-girders in order to access the bottom side of span over water. In the meantime all concrete surfaces were repaired and bridge equipment such as drainage and guardrails were repaired. Traffic was not limited during strengthening operations, and bridge has been upgraded with loading capacity straight after the repair works were finished.

\section{BOTTOM VIEW}

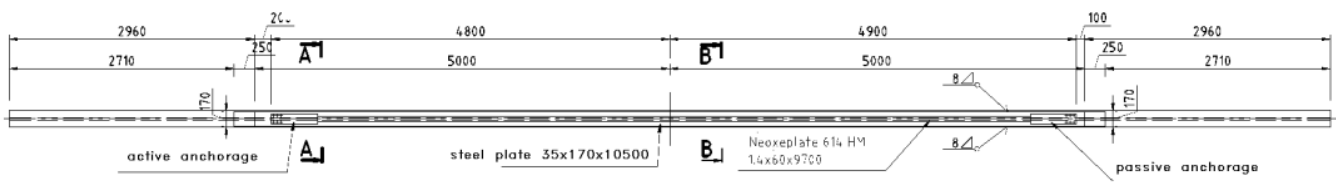

SIDE VIEW

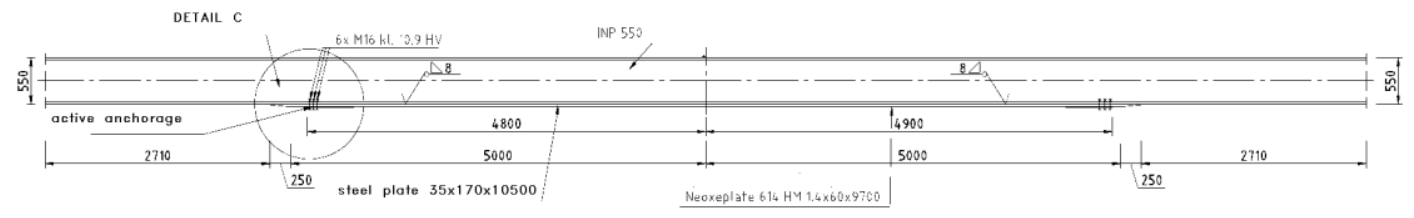

DETAIL C

\section{SECTION A-A SECTION B-B}
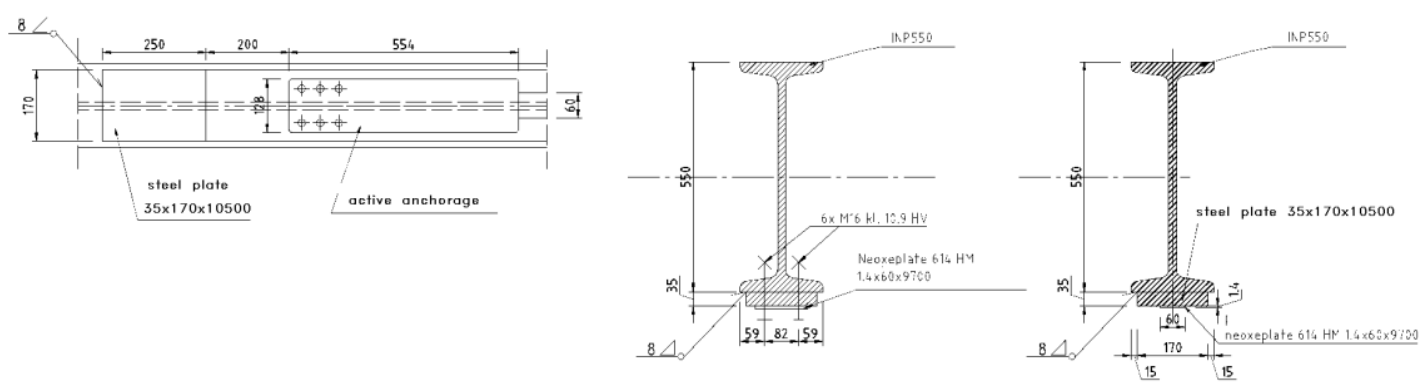

Figure 8: Details of application of CFRP strips to steel beam 


\section{Conclusions}

The strengthening of bridges with prestressed CFRP strips has proven to be an effective alternative to unstressed (passive) CFRP. The bending carrying capacity and stiffness of both concrete and composite spans can be considerably enhanced. As a result the utilization of CFRP strips is much more effective than in passive applications. But it has been clearly revealed that without mechanical anchorages there are peeling failures at the strip's ends. Therefore the still development in CFRP strips anchorage systems has been recently observed. One of such proposals is the Neoxe Prestressing System, which has been proved at Rzeszow University of Technology [8,9]. The NPS development program includes future laboratory testing of NPS-strenghtened RC and steel beams as well as field testing of NPSupgraded bridges. The results of these research works will be published as soon as they become available in subsequent publications.

\section{References}

[1] Meier, U. (1992). Carbon Fiber - Reinforced Polymers: Modern Materials in Bridge Engineering. IABSE, Structural Engineering International, 2(1), 7-12.

[2] Andrä, H-P., Maier, M. (2000). Post-strengthening with Externally Bonded Prestressed CFRP Strips. In Report of the $16^{\text {th }}$ Congress of IABSE, Lucerne 2000 (1507-1514). Lucerne.

[3] Berset, T., Schwegler, G., Trausch, L. (2002). Verstärkung einer Autobahnbrücke mit vorgespannten CFK-Lamellen. tec-21, 128(22), 27-29.

[4] EL-Hacha, R., Gren, M., Wight, G. (2003). Innovative System for Prestressing FiberReinforced Polymer Sheets. ACI Structural Journal, 100(3),.305-313.

[5] Garden, H.N., Hollaway, L.C. (1998). An Experimental Study of the Failure Modes of Reinforced Concrete Beams Strengthened with Prestressed Carbon Composite Plates. Composites, Part B, 29(4), 411-424.

[6] Meier, U., Kotynia, R. (2006). Strengthening Reinforced Concrete Structures with Prestressed Composite Materials. Inżynieria i Budownictwo, LXII(11),.596-599.

[7] Łagoda, M. (2005). Strengthening Bridges with Bonded Elements. Monografia 322. Seria: Inżynieria Ladowa. Krakow: Politechnika Krakowska.

[8] Siwowski, T., Michałowski, J., Błażewicz, S. (2010). The New System for CFRP Prestressing in Bridge Strengthening. Inżynieria i Budownictwo, LXVI(3), 152-156.

[9] Żółtowski, P., Siwowski, T. (2011). The Introductory Research on Strengthening Efficiency of RC Beams with Prestressed CFRP Strips. Inżynieria i Budownictwo, LXVII(9). 